\title{
Las reformas económicas en América Latina y los desafíos del nuevo decenio
}

\author{
Ricardo Ffrench-Davis
}

América Latina ha vivido un periodo de profundas reformas económicas. Estas fueron particularmente intensas durante los noventa, pero también hay casos más precoces en el Cono Sur; especialmente en Chile, que datan de la década de 1970. En todas estas experiencias se produjeron cambios dramáticos en la dimensión del Estado - limitación en su campo de acción, reducción de las cargas tributarias, privatizaciones masivas, disminución del gasto e inversión pública muy notable- que les otorgaron mucho más espacio a los agentes privados. El desempeño económico de América Latina en este nuevo decenio dependerá, en mucho, de la rectificación que haga de las principales falencias que aquejan a la región hoy. Ellas están asociadas a las fallas e insuficiencias de las reformas efectuadas en los noventa, en el marco del llamado "Consenso de Washington". Un decenio de reformers ha dejado resultados positivos en diversos aspectos. Erradicación de la hiperinflación, balances fiscales más equilibrados, ange de las exportaciones. Pero, en lo fundamental, que es el crecimiento económico y la equidad, el desempeño ha sido mediocre. Apenas un crecimiento del producto (PIB) de 2,7\% por año entre 1999 , 2001, y 10 millones de pobres más que en 1990. En este articulo, hacemos una revisión sucinta de la necesidad de reformas y de las que se han realizado desde los noventa (sección 1), los logros (sección 2), las falencias (sección 3), los desafios en el mevo decenio y lo que denominamos reformas de las reformas (sección 4).

' John Williamson (1998) analiza la aplicación del Consenso de Washington en Louis Emmerij (ed.). El desarrollo económico y social en los umbrales del siglo XXI, (BID). CEPAL ha venido desarrollando una profunda reflexión sobre la América Latina desde los '90. Parte de los aportes ha quedado reflejada en documentos tales como Equidad, desarrollo y ciudadania (CEPAL, 2000) y Crecer con estabilidad (CEPAL, 2001), donde se evalúan las reformas desde el punto de vista de la transformación productiva con equidad, en un enfoque de desarrollo integrado. En cuando a la reflexión personal, hemos abordado el análisis de las reformas en América Latina, en Macroeconomia, comercio, finanzas: para reformar las reformas en América Latina, donde nos ocupamos del diseño de las reformas, sus deficiencias y cómo rectificarlas, para lograr crecimiento con equidad. 
Necesitábamos reformas? Indudablemente que sí. La América Latina de 1990, así como los primeros países que echaron a andar sus reformas en los años setenta (Chile, en parte Argentina y Uruguay) necesitaban reformas. Teníamos economías sobreintervenidas, con un sector privado restringido y reglas poco transparentes. $\mathrm{La}$ economía necesita un sector privado (entendido no sólo como las empresas sino también compuesto por los trabajadores, las organizaciones sociales, etc.) vigoroso, junto con un sector público modernizado, profesionalizado, y que trabajen armónicamente. Este enfoque integrado, de funcionamiento coordinado de estas dimensiones, es esencial para que un país progrese de manera sostenida, sin explosiones, a través del tiempo.

¿Primera vez que América Latina tiene reformas? No. La región ha tenido muchas reformas a través del tiempo, pero con distintos signos. En los sesenta, en muchos casos hubo reformas que incluyeron estatizaciones; era en parte la moda de la época. La tonalidad de las reformas actuales, las neoliberales, es su búsqueda de reducir el espacio del sector público. Como se dijo, en muchos casos se justificaba un movimiento en esa dirección; sin embargo, éste ha sido demasiado abrupto e intenso, y falto de realismo: las masivas privatizaciones en América Latina, las intensas liberalizaciones comerciales y financieras, las modificaciones en las cuentas fiscales han implicado cambios muy abruptos, con secuencias equivocadas y con vacíos graves.

\section{Las reformas neoliberales \\ apuntan a reducir el espacio del sector público.}

Estas reformas han sido, en general, lineales. Más de lo mismo. Han tendido a moverse siempre en la misma dirección y a otorgarle a cada reforma un carácter de objetivo y no de medio, que es lo que son. En economía sabemos que, frecuentemente, el máximo no es el óptimo; hay puntos intermedios, hay velocidades más convenientes que otras y el problema de las modas de implementación de las reformas en los noventa fue siempre esta exigencia de más de lo mismo: luego de llegar a cierto objetivo, se sigue corriendo la meta sin preocuparse de las velocidades y de qué efectos están generando en paralelo las reformas, y de si faltan complementos esenciales para que esas reformas resulten eficaces. Esto es desconocer que la economía no es una suma de componentes aislados, sino un sistema donde el funcionamiento de una parte depende de qué está pasando simultáneamente con las otras.

La armonía de cómo se van moviendo la reforma comercial, el sistema tributario, el tipo de cambio, la tasa de interés, la innovación tecnológica, el ambiente macroeconómico, las regulaciones de los servicios públicos y la supervisión prudencial del sistema financiero, van, cada uno de ellos, afectando el buen o mal resultado de las otras variables. Por lo tanto, es vital no caminar hacia las reformas 
per se, sino llevar a cabo las reformas funcionales para lograr los objetivos de crecer más y crecer con más equidad. En un enfoque integrado, la equidad no viene expost sino que se va incorporando en el sistema productivo, porque en la medida en que la gente y las empresas grandes, pequeñas y medianas saben hacer cada día mejor las cosas, se consigue desarrollo económico y social o crecimiento con equidad.

\section{Para llevar a cabo las reformas}

\section{funcionales hay que crecer más y con más equidad.}

Dentro del espíritu del Consenso de Washington, se buscaba que las reformas tendieran a conducir a precios correctos y que fueran amigables con el mercado. Éstos son dos principios muy importantes y que comparto plenamente. Sin embargo, los resultados han ido en la dirección contraria. Por una parte, los precios macroeconómicos clave -el tipo de cambio y la tasa de interés- han tendido a desalinearse, a tomar valores incorrectos (outliers), exhibiendo mucha inestabilidad luego de las reformas en los noventa. Esto resulta muy poco amigable con el mercado, pues somete a una enorme tensión al sector productivo: ¿con qué tipo de cambio toma sus decisiones a largo plazo cuando tenemos una montaña rusa de apreciaciones y depreciaciones reales, o tenemos repentinamente tasas de interés reales de $5 \%$ y después tasas de $40 \%$ - $50 \%$ ? Las reformas han sido inspiradas por objetivos sanos: una economía de mercado con un mejor funcionamiento de las empresas que, consiguientemente, favorezca la generación de empleo productivo y el aumento de la productividad. Esto, a su vez, se reflejaría en un incremento sostenido de los salarios a través del tiempo.

Pero, como veremos, el resultado se ha desviado mucho de lo ideal. Una evaluación seria - una buena rendición de cuentas, lo que ha estado más bien ausente-contempla tanto los puntos positivos como los negativos.

\section{LOS LOGROS}

Entre los logros hay conquistas importantes, como las siguientes:

a) En lo comercial, ha habido un gran crecimiento de las exportaciones. Éste es un fenómeno generalizado a través de la América Latina de los noventa. Los volúmenes exportados han crecido de manera muy sustancial, a una tasa de $9 \%$ anual en términos reales durante diez años. ¿Cómo sabemos que este resultado es bueno? Primero, comparativamente, este desempeño es muy superior al de los años sesenta y setenta, y es algo mejor que en los años ochenta, que es la época de la crisis de la deuda, donde era muy importante exportar para poder pagar la deuda acumulada en los setenta. Segundo, las exportaciones mundiales crecen más lentamente que en América Latina: el impulso exportador promedio de América Latina fue un 50\% más rápido que el aumento de las exportaciones del mundo en la misma época; un hecho muy meritorio. 
b) Los equilibrios fiscales. En los ochenta, América Latina exhibió desequilibrios fiscales muy elevados, con países con déficit del orden de 10-17\% del PIB, en parte asociados a la crisis de la deuda. En efecto, el servicio de la deuda externa pública, proveniente a veces de deudas privadas "estatizadas", en un contexto de tipos de cambio que tuvieron que ser fuertemente devaluados, se encareció de manera apreciable. En los noventa se registra un gran cambio en los balances presupuestarios de América Latina, donde varios países aparecen con superávit fiscales durante muchos años, 0 déficit moderados: América Latina, en promedio, cumplía con el criterio de Maastricht, antes de la crisis asiática, con un déficit fiscal del orden de 1,5\% del PIB, inferior al 3\% límite del compromiso con la U.E. Este cambio implica un reconocimiento concreto de que no es posible gastar lo que no se tiene. Un déficit fiscal muy fuerte, por demasiado tiempo, no es sostenible, porque termina por revertirse en contra del país y de las autoridades.

\section{Un déficit fiscal muy fuerte y prolongado termina por volverse contra el país y las autoridades.}

c) El control de la inflación. En este ámbito, América Latina experimentó una notable mejora con la desaparición de los procesos de hiperinflación de las décadas previas. En efecto, en los años setenta y ochenta hubo países con niveles de inflación de más de $1000 \%$ anual, lo que es muy destructivo para las empresas y las personas. Tener que estar corriendo en el curso del día para comprar para que no se le desvalorice el dinero conspira contra el normal desarrollo de la economía, y es un enemigo mortal de la inversión, la innovación, la equidad y la armonía social. En los noventa, han desaparecido estos niveles de inflación, dando paso a tasas de un dígito como las predominantes. En 2001, el nivel promedio fue de 7\% anual, 10 que constituye un avance muy sustancial.

\section{LAS FALENCIAS}

Las reformas han adolecido también de graves y reiteradas deficiencias. Entre las sobresalientes, destacan:

\section{a) Exportaciones con bajo valor agregado}

El mayor impulso exportador con mucha frecuencia ha sido acompañado de un impulso más fuerte en las importaciones. Así como en el presupuesto fiscal el gasto debe ser financiado, las altas importaciones también deben ser financiadas, principalmente por las exportaciones. ¿ $Y$ cómo se ha financiado lo que no es cubierto por las exportaciones? Con endeudamiento externo y con flujo de capitales. En el decenio reciente, los recursos llegaron a través de los flujos de fondos de inversión a las bolsas, los depósitos de moneda extranjera, las colocaciones de bonos, los mercados de derivados, etcétera.

Entonces, así se gestaron los desequilibrios externos de los noventa. Éstos 
no surgen por casualidad, sino que responden a la manera de hacer política económica y de reformar el funcionamiento de las economías y, evidentemente, a la disponibilidad de una oferta externa entusiasta. La experiencia reciente de la región muestra un fuerte crecimiento de los déficit externos y eso ineludiblemente genera vulnerabilidades. América Latina la sufrió en 1995, con la crisis mexicana, y luego, desde 1998, con la crisis asiática. No es teoría sino la dura realidad la que ha afectado a una enorme proporción de la población y de las empresas de nuestros países. Las crisis han sido muy seguidas: hay países que han tenido dos crisis intensas con tres o cuatro años de por medio, lo que significa que no se terminan de recuperar de una cuando llega la otra. Esto no es exclusiva mala suerte, sino que responde a los desequilibrios que se han creado como fruto de la manera de hacer política macroeconómica, política comercial y política financiera (véase Ffrench-Davis, 1999).

\section{b) Balance fiscal que no prioriza la} modernización productiva y social

En lo fiscal, si bien se han logrado presupuestos rebalanceados, frecuentemente se ha hecho con costos asociados a las reducciones generalizadas de gastos. Por ejemplo, hay una insuficiencia de inversión en capital humano. Los sistemas educacionales necesitan ser reforzados en América Latina, y eso requiere de recursos y de eficiencia en su gasto. Lo que predomina, sin embargo, son bajos salarios de los profesores, muy poco esfuer- zo en su capacitación y en la renovación de programas de enseñanza. El mundo cambia, los programas se tienen que ir acondicionando persistentemente.

\section{En América Latina hay que reforzar los sistemas educacionales, para lo cual se necesitan recursos y eficiencia en su gasto.}

Todas estas transformaciones no se registran en forma espontánea, no las hace el sector privado, aunque pueda colaborar enormemente en su diseño y concreción. Muchas acciones se pueden descentralizar, pero la conducción tiene que ser por parte de las autoridades políticas de la Nación. Subsiste una insuficiencia de gasto, de esfuerzo y de reflexión en ese terreno. En varios países, están en marcha reformas de las reformas, pero lo que necesitamos es aumentar la velocidad. No se trata de gastar recursos a ciegas, sino de dirigirlos a la mejora de la calidad de los sistemas educacionales y a cubrir la necesidad de mayor capital humano, lo que redundará en un aumento de las posibilidades de crecimiento económico y de alcanzar, en paralelo, mayor equidad en la distribución de oportunidades y de la productividad.

Asimismo, en muchos países hay insuficiencia de gastos de infraestructura. Se puede avanzar en la descentralización y participación del sector privado, con los sistemas de concesiones. Esto ayuda a aliviar la carga del sector público para que pueda concentrar sus energías en las muchas otras necesidades que hay que cu- 
brir en los países, pero -otra vez- es un proceso que tiene que ser programado. No funciona descentralizadamente sin una conducción.

En cuanto a la otra parte del presupuesto, la de los ingresos tributarios, ha habido avances en los noventa, pero que son modestos. Es imperioso hacer un esfuerzo mucho más intenso. Para la equidad: igual ingreso, igual tributación. Todavía existen grandes vacíos en los sistemas tributarios y demasiada evasión en comparación con las economías desarrolladas.

En suma, no podemos limitarnos a tener equilibrio presupuestario sin mirar al interior de los requerimientos de gasto fiscal, y su financiación, para modernizar nuestras economías.

\section{c) Mala distribución de las oportuni- dades}

El desafío de la equidad. En el 2000 había 210 millones de pobres en América Latina (un $35 \%$ de la población), 10 millones más que en 1990. Ello se explica, en parte, por el ajuste recesivo de 1999. Una de las conclusiones que se han fortalecido en los noventa es el conocimiento de cómo las crisis afectan regresivamente a nuestras sociedades. Hay trabajos muy interesantes, como el de Dani Rodrik (2001), que refuerzan el mismo planteamiento de que en cada una de las instancias de crisis financieras hay una intensificación de la pobreza y de la regresión distributiva. Las crisis no son neutras entre sectores, afectan a innumerables empresas y personas, a consumidores y productores, con un sesgo regre- sivo, caen más los que están en los quintiles de menores ingresos. La recuperación posterior no es automática sino lenta, lo que deja una significativa pérdida de ingreso y patrimonio para los grupos más pobres, con una huella regresiva por mucho tiempo.

\section{Las crisis no son neutras entre sectores y afectan a innumerables empresas y personas.}

Por ejemplo, el salario promedio mexicano el año 2000 era $15 \%$ menor que en 1994, seis años después. Ésa es la huella de la crisis del "Tequila" de 1995. La pobreza intensa es un símbolo de falta de modernidad, signo de subdesarrollo. Tenemos que hacer lo opuesto. Esto parte por constatar que las crisis financieras tienen signo regresivo y, por lo tanto, que se precisa reformar la manera de hacer macroeconomía.

\section{d) Insuficiente inversión productiva}

Sin duda, uno de los aspectos donde las reformas exhiben un desempeño más mediocre es en el de la insuficiente inversión productiva $\mathrm{y}$, consecuentemente, en el pobre crecimiento económico. $\mathrm{La}$ América Latina de los años noventa invirtió 5 puntos del PIB menos en promedio que en los setenta, e invirtió sólo un punto más que en los ochenta (véase el Gráfico 1, en Anexos). Se podría decir que estamos mejor que en los ochenta, pues entonces el PIB creció 1,3\% anual y en los noventa se expandió $2,7 \%$, pero los 
ochenta fueron la década perdida, por lo que no es el patrón de comparación apropiado.

Ése es un error repetido. Muchos de los estudios empíricos de evaluación de las reformas neoliberales comparan resultados de los noventa con los ochenta y concluyen que las reformas funcionaron bien porque estamos creciendo más, pero la realidad es que $2,7 \%$ es la mitad de 10 que América Latina creció por año entre 1950 y 1980 (véase el Cuadro 1, en Anexos). Un conjunto de 19 países, con buenos y malos años durante esos tres decenios, entrega una tasa de crecimiento promedio de $5,6 \%$. Es decir, en los noventa se registra una velocidad que es la mitad de aquel ritmo que no era satisfactorio, pues no estábamos satisfechos con la América Latina de 1950 a 1980. Por lo tanto, aún hay mucho que mejorar.

Es clave invertir más y mejor. No hay país en el mundo que haya crecido de manera sostenida, sin haber invertido vigorosamente. Es frecuente dejarse engañar con tasas de crecimiento altas que son transitorias, pues muchas veces se basan en procesos de recuperación de la actividad económica y no de expansión fuerte de la capacidad productiva (Chile en 1985-89; Argentina en 1992-94 y 1997). Es importante aprovechar la recuperación, pero la clave es reactivar de manera que las inversiones y las mejoras de productividad logren que el crecimiento alto sea sostenido después de terminada la reactivación.

Una excepción interesante en la América Latina de los noventa fue Chile. Entre 1990 y 1998 Chile creció 7\%. En
1999 el PIB cayó $1 \%$, por lo que el promedio de la década fue del orden de $6 \%$ (Ffrench-Davis, 2001). Detrás de este aumento sostenido del producto está la elevada tasa de inversión productiva (equipos, maquinarias, infraestructura, construcción comercial y residencial). En los años noventa, Chile invirtió 10 puntos del PIB más que durante el gobierno de Pinochet (1974-89). América Latina, en cambio, invirtió 5-6 puntos menos que en los setenta (véase el Gráfico 1, en Anexos). Ésa es una razón determinante de porqué Chile creció 5,5\% y América Latina sólo $2,7 \%$ en 1990-2001.

\section{No hay país en el mundo que haya crecido en forma sostenida sin haber invertido vigorosamente.}

\section{e) El caso argentino}

El caso argentino ilustra con claridad las falencias prevalecientes en las reformas. Argentina era presentada por la visión neoliberal, en la mayor parte de los noventa, como un caso muy exitoso de reformas. Su llamada "ley de convertibilidad", que fijó su tipo de cambio a un peso por un dólar en 1991, gozó de amplio prestigio. Se liberalizaron abruptamente las importaciones y el mercado de capitales en el mismo año.

El PIB creció con vigor en los años siguientes a la derrota de la hiperinflación: un $8,1 \%$ en $1991-94$ y $6,8 \%$ en $1996-97$ (véase el Cuadro 2, en Anexos). Pero hubo una impresionante desconsideración de 
fundamentos económicos; por ejemplo: i) los años negativos, y el hecho evidente de que mucho del alza del PIB efectivo consistía en el aprovechamiento de capacidad subutilizada existente en 1990 y en 1995, con la subsistencia de una tasa de inversión modesta; ii) el fuerte atraso cambiario que se registró en 1991-92, mientras la inflación descendía desde sus elevadas alturas, hecho que ocurrió rápido pero no instantáneamente; con ese atraso, la economía argentina quedó cazada en un precio del dólar fuera de equilibrio.

\section{La trampa cambiaria es la principal causa económica de la situación argentina.}

La percepción que tuvieron "los mercados" queda reflejada en que los evaluadores de riesgo otorgaron buenas calificaciones a Argentina hasta avanzado 1998. Es muy interesante, además, constatar que recibe un trato similar a México, país que parecía ascendido a la categoría de "desarrollado", al entrar al NAFTA y a la OCDE (club de las naciones más ricas). E1 gráfico 3 (en Anexos) muestra los spread de Argentina y México, y su tránsito compartido hasta 1999.
Luego de que la "ley de convertibilidad" logró su objetivo de eliminar la hiperinflación en 1991, en los siguientes años de boom económico en Argentina y de optimismo o euforia entre los ofertantes de fondos a las economías emergentes (1992-93 o 1996-97), el tipo de cambio debió haber sido flexibilizado por el gobierno argentino. Ello no habría provocado entonces ningún trauma. Con la flexibilización, luego, Argentina habría podido enfrentar oportunamente la llegada del contagio de la crisis asiática. La trampa cambiaria es la principal causa económica de la situación dramática que vive hoy. La reiterada repetición de que son la ausencia de reformas del Consenso de Washington y el déficit fiscal las causas de su crisis no tiene base real. Su situación fiscal era evidentemente deficiente, pero no explica la gravedad del entorno económico. Como lo recuerda Guillermo Calvo, ex investigador del FMI y economista jefe del $\mathrm{BD}$, el déficit fiscal argentino fue inferior al $2 \%$ del PIB ${ }^{2}$. Sólo luego de surgida la crisis se disparó el déficit. El problema central fue la dolarización, con pasivos en dólares y un tipo de cambio que no reflejaba la realidad económica. Con una prolongada sequedad de los mercados financieros internacionales desde 1998, la trampa cambiaria se tornó explosiva. Ello, $\sin$ duda, fue reforzado por la irresponsabilidad del último año del gobierno de Menem y, luego, por la notable indecisión de su sucesor.

2 G. Calvo, “¿Qué estuvo mal en Argentina?”, El Mercurio, Grupo de Diarios de América, 25 de abril de 2002, pág. B8. 
¿CÓMo MEJORAR EL DESEMPEÑo? LA NECESIDAD DE REFORMAR LAS REFORMAS

Dada la heterogeneidad de los resultados de las reformas económicas, con sus rasgos positivos y negativos, es vital aplicar cambios que tiendan a conservar las características saludables y a corregir los errores más graves. En el fondo, se trata de introducir reformas a las reformas.

En el caso de Chile, al recuperar la democracia en 1990, se produjeron reformas de las reformas. No hubo destrucción sino construcción sobre lo existente, mejorándolo. Reforma tributaria para aumentar el gasto social. Reforma laboral para equilibrar el mercado del trabajo y rebalancear el poder entre los sectores de la sociedad. Reformas macroeconómicas para tener una economía más sostenible, que significó ir contra la moda de abrir indiscriminadamente la cuenta de capitales; en vez de seguir esa moda, se introdujo una regulación prudencial macroeconómica sistemática, se aplicó una apertura selectiva de los flujos de capitales; se perfeccionó la supervisión prudencial del sistema financiero, ya bastante estricta; aplicación sistemática de un fondo de estabilización del cobre; algunos esfuerzos deliberados para desarrollar el segmento de largo plazo del mercado de capitales, políticas cambiaria y monetaria activas, y una política fiscal muy responsable: cada nuevo gasto extra tuvo su financiamiento efectivo en el presupuesto global.

Algunos de los principios de política económica que deben guiar esta búsqueda por un mayor bienestar para la pobla- ción -resultantes de crecer con equidadson los siguientes:

\section{Cuando Chile recuperó la democracia no hubo destrucción sino construcción sobre lo existente.}

\section{a) Evitar precios macroeconómicos incorrectos}

Un elemento esencial para explicar la evolución de la inversión productiva son los precios que enfrentan los inversionistas. La tasa de interés y el tipo de cambio son señales muy importantes para casi todos los sectores de la economía: los exportadores, los que compiten con las importaciones, los que tienen que comprar bienes intermedios, bienes de capital. En América Latina, estos precios "macroeconómicos" han mostrado un comportamiento muy inestable: tasas de interés reales de $40-50 \%$ a veces, apreciaciones importantes seguidas de depreciaciones abruptas.

Es normal que haya variaciones de precios, pero el problema es en qué rangos, para que el agente que toma decisiones de inversión en cierto sector productivo para muchos años tenga una expectativa positiva del entorno económico cuando su producto salga al mercado.

Por eso, es fundamental preocuparse de que estos precios macroeconómicos -que afectan al conjunto de agentes económicos y a la demanda agregada- sean relativamente estables y no estén demasiado desalineados o desequilibrados. Eso depende de variables de política econó- 
mica y de cómo se organizan los mercados. Por ejemplo, la tasa de interés va a situarse en un nivel mucho más adecuado si existe un sistema de regulación prudencial bancaria, que garantice un funcionamiento transparente de quién, a quién y cómo se presta. Los resultados de débil regulación y supervisión prudencial han sido desastrosos en América Latina, con crisis financieras con costos gigantescos para el fisco; por ejemplo, las crisis bancarias y de balanza de pagos de Chile en 1982-83, y de México en 1995.

\section{Es fundamental preocuparse de que}

los precios macroeconómicos sean relativamente estables.

En esa misma línea es muy influyente el espacio que tengan las autoridades para hacer política monetaria y cambiaria. En una economía dolarizada, tipo ley de convertibilidad al modo de la argentina, no hay espacio. Lo contrario sucede con una política de tipo de cambio administrado por el banco central, que evite cotizaciones extremas, que se ajusta de acuerdo a la tendencia de mediano plazo y no según las fluctuaciones cíclicas de precios de recursos naturales o de los mercados financieros de corto plazo.

Por estas razones, resulta clave la elección que se haga de régimen cambiario. Las opciones que están hoy más de moda se limitan a dos extremos: por un lado, un tipo de cambio fijo o dolarización, que implica renunciar a la moneda nacional y a hacer política cambiaria y monetaria y, por otro lado, un tipo de cambio totalmente libre, que es tremendamente sensible a los flujos de capitales golondrina, de naturaleza muy volátil; el resultado es un tipo de cambio notablemente inestable. Sin embargo, hay que mirar más allá de las modas, y encontrar una respuesta pragmática al problema, con una flexibilidad administrada del tipo de cambio.

b) La regulación prudencial de los movimientos de capitales

América Latina ha sido muy afectada por los shocks financieros, con un impacto desestabilizador muy fuerte sobre su entorno macroeconómico (ver Gráfico 2, en Anexos).

Al revisar la historia de las últimas décadas, se constata gran abundancia de créditos bancarios externos en 1977-81. Había cien países en desarrollo con acceso masivo a los mercados de créditos bancarios internacionales alrededor de 1980 , con una oferta de fondos mayor que lo que eran capaces de absorber eficientemente. Luego vino la escasez de los ochenta, que duró casi un decenio, en que no había financiamiento voluntario para ninguna nación latinoamericana. Todo el financiamiento era forzado a través de las negociaciones con el FMI y los comités de los bancos acreedores.

En 1991-94, se produjo un resurgimiento acelerado de los flujos financieros hacia las economías latinoamericanas. La nueva oleada fue muy significativa como proporción del PIB (similar a la de 1977-81). Esta vez, hubo una composición mucho más variada, ahora con un 
segmento fuerte de inversiones de cartera. De cada 4 dólares de entradas netas sólo uno correspondió a inversión extranjera directa-de naturaleza irreversible, de largo plazo-, mientras la gran mayoría llegó en la forma de inversiones de cartera, más líquida, de corto plazo. Los nuevos capitales permitieron al inicio que las deprimidas economías del continente pudieran reactivarse. Sin embargo, en muchas de ellas, con el transcurso del tiempo, comenzaron a gestarse problemas de vulnerabilidad ante shocks externos, por la vía de permitir excesivos déficits en cuenta corriente, apreciaciones cambiarias desproporcionadas y stocks de pasivos externos que se fueron elevando de manera peligrosa.

La vulnerabilidad estaba estrechamente asociada a un nivel alto de deuda y a un componente elevado de corto plazo, déficit externo significativo y precio bajo del dólar. Para descubrir en qué medida las políticas seguidas pueden hacer la diferencia, observemos lo sucedido con Chile y México. Ambos países presentaban indicadores macroeconómicos muy similares en 1988-89: ahorraban tasas parecidas de su PIB, tenían un alto uso de su capacidad productiva (a diferencia de países como Argentina y Perú), y sus economías se encontraban relativamente ordenadas. Sin embargo, al producirse el resurgimiento de los capitales, ambos se diferenciaron diametralmente en su posición frente a ellos. México adoptó el camino de recibir "todo lo que venga", y Chile adoptó el camino de "no repetir la historia de 1982 ", y por lo tanto desalentó el exceso de fondos de corto plazo y volátiles.

\section{Cuando hay grandes entradas de dólares, se gastan en productos importados y el país queda con la deuda y sin capacidad para generar los recursos para pagarla.}

Chile, en 1982, tuvo la crisis más grande de América Latina. Ya había reformado su economía en los años previos, se habían liberalizado las importaciones, y había mantenido un superávit fiscal por varios años; no obstante, en 1982 su PIB cayó $15 \%$ y el desempleo abierto llegó a $31 \%$ de su fuerza de trabajo, manteniéndose muy alto por varios años. Las autoridades del nuevo régimen democrático asumido en 1990 estaban conscientes de que cuando el endeudamiento es excesivo, se empieza a inflar la economía, y el tipo de cambio y los precios bursátiles se desequilibran. Se sabía que cuando los capitales financieros llegan de improviso, no se dirigen al proceso de inversión porque el inversionista productivo necesita tiempo para identificar proyectos; la inversión es un largo proceso y cualquier productor requiere un plazo desde que decide invertir hasta que se asoman al mercado las primeras unidades de su producción. Lo que sucede, entonces, es que los nuevos recursos financieros que 11egan abruptamente se dirigen al consumo. En particular, en estos períodos de grandes entradas de dólares, naturalmente, los dólares se gastan en productos importados; entonces el país queda con la deuda y sin una capacidad productiva para generar los recursos que le permitan respon- 
der a ella. Luego, cuando viene el ajuste recesivo, por el cobro de la cuenta, éste es muy doloroso y no se dispone de herramientas para absorberlo eficientemente. El resultado son los ajustes recesivos y regresivos, con desempleo, caída de actividad económica y descenso de la inversión productiva.

Las decisiones más determinantes son las tomadas en los momentos de auge; entonces es posible escoger si nos embarcamos por un sendero sostenible en el tiempo o si vamos a pasar por aceleradas y frenadas bruscas. Chile escogió en 1990 el camino de evitar las infladas y distorsiones que provocan los capitales financieros en volumen excesivo y limitó las entradas a lo que era posible absorber de manera eficiente, sin que el tipo de cambio se apreciase inadecuadamente, ni que el consumo aumentase de forma artificial con recursos transitorios. En efecto, la demanda debería aumentar sólo por los capitales que estarán invertidos productivamente en el país, como es el caso de la inversión extranjera directa cuando llega a crear nueva capacidad productiva (no a comprar la existente, que constituye sólo una transferencia de una capacidad productiva dada). Los resultados de la política prudencial de Chile pudieron observarse en 1995. La economía chilena creció $9 \%$, mientras que la mexicana entró en una recesión, con una caída del PIB de $6 \%$.

Con la crisis del tequila, los capitales golondrina huyeron de América Latina. Luego de la crisis, hubo una recuperación total de los flujos de capitales hacia la región entre mediados de 1995 y 1997.
Es impresionante comprobar que se vuelve a repetir la historia, comedia de equivocaciones: confundir recuperación con expansión productiva, observar alzas bursátiles no sostenibles por las utilidades de las empresas, déficits externos crecientes, atraso cambiario, persistentes mejoras de las calificaciones de riesgo soberano (notas colocadas por las agencias mundiales calificadoras de riesgo), y un sobreoptimismo del FMI sobre el desempeño económico.

\section{La demanda debería aumentar sólo por los capitales que estarán invertidos productivamente en el país.}

Con la crisis asiática, quedaron de nuevo al descubierto los desequilibrios y vulnerabilidades. Los flujos de capitales cayeron fuertemente en 1998. Estas caídas y subidas reflejan lo que sucede con el mundo de las finanzas especulativas, al margen del mundo real y del desarrollo productivo, que responde a la productividad, el empleo y las utilidades que la inversión es capaz de generar. Por ejemplo, el índice de precios bursátiles subió 300\% en 1991-1994, mientras que el PIB de la región creció $20 \%$ en el mismo período, reflejando que no hay relación entre estos vaivenes de corto plazo y los cambios en productividad (asociados al crecimiento del PIB por habitante). En 1998 se debió soportar una nueva depresión de los precios bursátiles por la llegada de la crisis asiática. El desequilibrio se gestó durante el auge de flujos de capitales en 1996- 
1997, cuando de nuevo se repitió el mencionado fenómeno de fuerte ingreso de capitales de corto plazo, atraso de tipos de cambio, burbujas en la bolsa, y acumulación de pasivos externos volátiles.

Estamos en presencia de un mundo en el que los movimientos de capitales han venido a afectar muy notablemente precios internos, como el tipo de cambio y los bursátiles. Es preciso estar atentos a estos precios, pues sabemos que cuando el mercado perciba que el precio de una acción se aleja demasiado del valor real de la empresa, vendrá, en algún momento, una brusca caída de él. Algo similar ocurre con los precios de bienes inmobiliarios, como sucedió en los países asiáticos, como Japón, Tailandia y Corea.

\section{c) Desarrollo sostenido e inversión social}

Para crecer sostenidamente, se requiere crear nueva capacidad productiva: mayor cantidad y calidad de capital y de trabajo, organización e institucionalidad funcional. En esta era de "globalización", ello se requiere para aprovechar las oportunidades que se presentan y eludir los peligros. Aquí destaca un papel clave para la educación y la capacitación laboral. Es urgente ampliar la cobertura y calidad de la educación, como un modo de acrecentar el capital humano. También, debe haber una preocupación por nivelar su calidad entre los distintos estratos sociales, para evitar la reproducción de la pobreza y entregar una mejor distribución de las oportunidades. La capacitación laboral es otra pieza fundamental para incrementar la productividad; es la manera "progresista" de flexibilizar el mercado por el lado de la oferta. Aquellos trabajadores que ya salieron del sistema educacional y que van a estar cuarenta años en la fuerza de trabajo ya no pueden volver a la primaria y secundaria; ellos requieren de capacitación durante su vida laboral. Éste es un principio que los países asiáticos -tales como Corea y Taiwán-pusieron en práctica de manera muy sistemática durante los tres decenios de espectacular desarrollo, con una distribución de ingresos que mejoró notablemente hasta mediados de los noventa. Por cierto, un esfuerzo eficiente y suficiente requiere cuantiosos recursos públicos y mucha eficiencia. Un tema con ribetes similares es el de la difusión tecnológica, en particular en las pymes. En capacitación laboral y en tecnología hay sustanciales externalidades y fallas de mercado que no se han corregido con decisión: ésa es una de las diferencias entre desarrollo y subdesarrollo.

\section{Quienes pueden aprovechar mejor los períodos de bonanza no sostenibles son los grupos de mayores ingresos.}

Como hemos visto, cuando se enfrenta una crisis, las personas y las empresas de menores recursos económicos tienen menos capacidad de protegerse $y$, como consecuencia, aumenta la pobreza y tiende a empeorar la distribución del ingreso. Del mismo modo, cuando se registra un período de auge no sostenible, son los grupos de mayores ingresos los que pue- 
den aprovechar mejor los beneficios de la bonanza. Esto plantea una responsabilidad muy fuerte del manejo macroeconómico.

Es un imperativo ético y técnico el generar condiciones más favorables para superar la pobreza y mejorar la distribución del ingreso, que eviten el surgimiento de tensiones y mayor desintegración social al interior de nuestras naciones. Se trata de participar en la globalización integrándonos internamente y no disgregándonos; queremos hacer nuestra globalización. La integración latinoamericana es uno de los instrumentos eficaces para avanzar en ese objetivo.

\section{d) El carácter integral del desarrollo}

Políticas mesoeconómicas, tales como la capacitación de la mano de obra; el fomento a la innovación y difusión del conocimiento técnico; el desarrollo de conglomerados (clusters) y de cadenas productivas que, conjuntamente con una mejor infraestructura, mejoren la competitividad sistémica; y el espacio para las pequeñas y medianas empresas, son esenciales para extender la productividad a través de la sociedad.

Como se expuso al inicio, necesitamos reformas amigables con el mercado (market friendly) y precios correctos (right prices), ambos rasgos sin duda esenciales para el crecimiento. Sin embargo, el magro desempeño actual indica que la amistad no ha sido fiable y que con frecuencia los precios macroeconómicos se han apartado del equilibrio. Tasas de interés y tipo de cambio fuertemente des- alineados dificultan, evidentemente, la evaluación de proyectos para la asignación de recursos, promueven la inversión especulativa por sobre la productividad y contribuyen a deteriorar la cartera de las instituciones financieras. Las crisis recurrentes ilustran situaciones que entrañan macroprecios extremadamente desalineados y una demanda agregada a niveles insostenibles.

Es sorprendente que los errores cometidos en las reformas financieras y cambiarias de Argentina y Chile en los años setenta se hayan repetido en otros países de la región desde mediados de los ochenta, y en países de Asia durante los noventa. No sólo comparten la debilidad de la supervisión prudencial, sino también los escenarios de booms de los segmentos de capitales de corto plazo y desplazamiento de ahorro interno, fuertes atrasos cambiarios y crisis financieras de elevado costo fiscal. Una efectiva "rendición de cuentas" está ausente, a juzgar por las frecuentes alabanzas que han recibido muchas reformas de diseño deficiente, cuyos objetivos no han sido alcanzados en plenitud o han desembocado en situaciones críticas.

El objetivo central de elevar el bienestar del conjunto de la población no se logrará sin avances significativos en la consolidación de economías dinámicas y competitivas, capaces de enfrentar los retos de un mundo globalizado. Equidad y desarrollo económico, incluida su dimensión de desarrollo sostenible, son, en este sentido, elementos de una misma estrategia integral (véase CEPAL, 2000). E1 desarrollo social no puede descansar ex- 
clusivamente en la política social, así como la política económica no puede por sí sola, aislada del diseño de la política social, asegurar objetivos socio-económicos. La generación de empleo e ingreso sostenible; la superación de heterogeneidades productivas heredadas y de reciente creación, potenciando la contribución de las pymes al desarrollo; la canalización de mayores recursos para el mejoramiento del capital humano y programas integrales de lucha contra la pobreza, en forma consistente con una sana política fiscal, son algunos de los elementos que conectan el desarrollo económico con el social.

\section{El desarrollo social no puede descansar sólo en la política social.}

En todos estos planos, los patrones de desarrollo económico no son "neutrales" en términos sociales y es posible, por lo tanto, encontrar y promover encadenamientos sociales más eficaces, que además incrementan el impacto de la política social. Al mismo tiempo, el desarrollo social, la reducción de la desigualdad y la eliminación de diversas formas de discriminación crean condiciones favorables para el desarrollo económico, como resultado de la inversión en capital humano y de la construcción de "capital social", que favorecen la competitividad sistémica de las economías en un mundo globalizado.

Políticas macroeconómicas que generen equilibrios sostenibles en la economía real y políticas de desarrollo productivo, consistentes con una mejor distribución de oportunidades y de productividades a través de la sociedad, son vitales para lograr aquel esquivo objetivo, que es el desarrollo económico con equidad en este nuevo decenio.

\section{BIBLIOGRAFIA}

CEPAL. Equidad, desarrollo y ciudadania, (Santiago, Naciones Unidas, 2000).

CEPAL. Crecer con estabilidad, (Santiago, Naciones Unidas, 2000).

Ffrench-Davis, R. Macroeconomía, comercio, finanzas: para reformar las reformas en América Latina, (Santiago, McGraw-Hill, 1999).

nes, 2001, segunda edición).

Rodrik, D. "¿Por qué hay tanta inseguridad en América Latina?", en Revista de la CEPAL N 73 , abril de 2001.

Williamson, J. "Revisión del consenso de Washington", en L. Emmerij (comp.). El desarrollo económico y social en los umbrales del siglo XXI, (1998). 


\section{AnEXos}

Cuadro 1

AMÉRICA LATINA: PRODUCTO INTERNO BRUTO, 1971-2001

(tasas de crecimiento anual, \%)

\begin{tabular}{|l|c|cc|c|c|c|c|c|}
\hline & $1970-80$ & $1981-89$ & 1990 & $1991-94$ & 1995 & $1996-97$ & $1998-01$ & $1990-01$ \\
\hline Argentina & 2.8 & -0.7 & -2.0 & 8.0 & -2.9 & 6.7 & -1.2 & 2.9 \\
Brasil & 8.6 & 2.3 & -4.6 & 2.8 & 4.2 & 2.8 & 1.7 & 1.9 \\
Chile & 2.5 & 3.0 & 3.3 & 7.4 & 9.0 & 6.8 & 2.8 & 5.5 \\
Colombia & 5.4 & 3.7 & 3.2 & 3.9 & 4.9 & 2.6 & 0.2 & 2.5 \\
México & 6.7 & 1.5 & 5.1 & 3.5 & -6.1 & 6.1 & 3.9 & 3.4 \\
Perú & 3.9 & -0.7 & -5.5 & 4.9 & 8.6 & 4.6 & 0.9 & 2.9 \\
Uruguay & 3.0 & 0.0 & 0.4 & 5.6 & -2.3 & 5.2 & -1.0 & 2.2 \\
\hline América & 5.6 & 1.3 & -0.6 & 4.1 & 1.1 & 4.4 & 1.7 & 2.7 \\
Latina (19) & & & -0.6 & & & 4.7 & & \\
\hline
\end{tabular}

Fuente: CEPAL, expresado en dólares de 1980 para 1971-80, en dólares de 1990 para 1981-90 y en dólares de 1995 para 1991-2001.

Cuadro 2

ARGENTINA: INDICADORES MACROECONÓMICOS, 1992-2001.

\begin{tabular}{|c|c|c|c|c|c|}
\hline & $\begin{array}{l}\text { Promedio } \\
1992-97\end{array}$ & 1998 & 1999 & 2000 & 2001 \\
\hline Crecimiento del PIB ${ }^{a}$ & 5.2 & 3.9 & -3.3 & -0.8 & -4.5 \\
\hline Inflación ${ }^{\mathrm{b}}$ & $1.5^{\mathrm{c}}$ & 0.7 & -1.8 & -0.7 & -1.5 \\
\hline Balance fiscal $^{d}$ & -0.5 & -1.4 & -1.7 & -2.4 & -3.5 \\
\hline Índice de salarios $(1995=100)^{\mathrm{e}}$ & 100.4 & 99.0 & 100.1 & 101.6 & 100.2 \\
\hline $\operatorname{TCR}(1987-90=100)^{\mathrm{f}}$ & 62.3 & 64.2 & 56.6 & 57.3 & 56.3 \\
\hline Riesgo país ${ }^{\mathrm{g}}$ & 405.7 & 630.5 & 460.4 & 747.7 & 3750.3 \\
\hline
\end{tabular}

Fuente: CEPAL, sobre la base de cifras oficiales y Ffrench-Davis (1999).

${ }^{a}$ Variación porcentual anual. Dólares de 1995.

${ }^{b}$ Porcentajes de variación anual. Diciembre-diciembre.

${ }^{c}$ Considera promedio 1994-97 para reflejar mejor la gran estabilidad de precios lograda.

${ }^{d}$ Porcentajes del PIB. Sector público no financiero.

${ }^{\mathrm{e}}$ Industria manufacturera.

'Ponderado por exportaciones.

${ }^{\mathrm{B}}$ Índice de JP Morgan. Valores de diciembre de cada año. 


\section{Gráfico 1}

AMÉRICA LATINA: Inversión bruta fija, 1977-2001

$(\%$ del PIB)

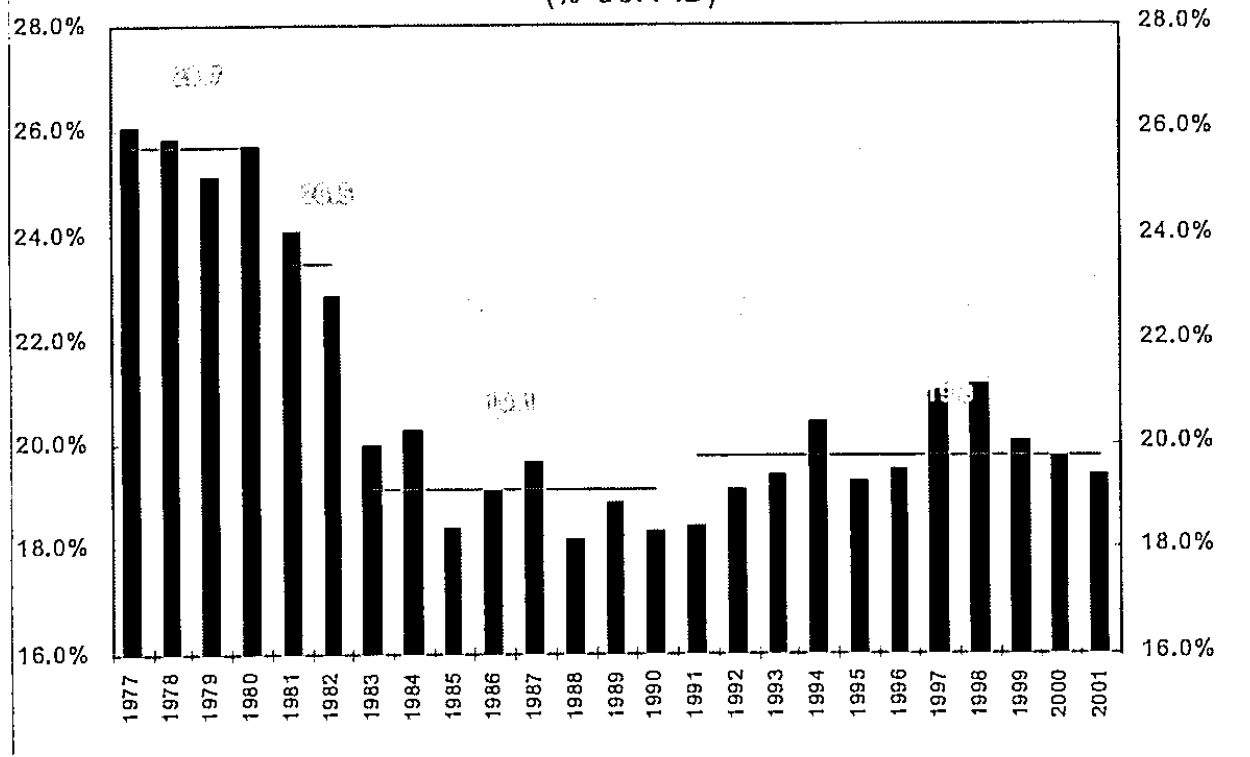

Fuente: CEPAL, sobre la base de datos oficiales para 19 paises. Datos escalados a precios de 1995.

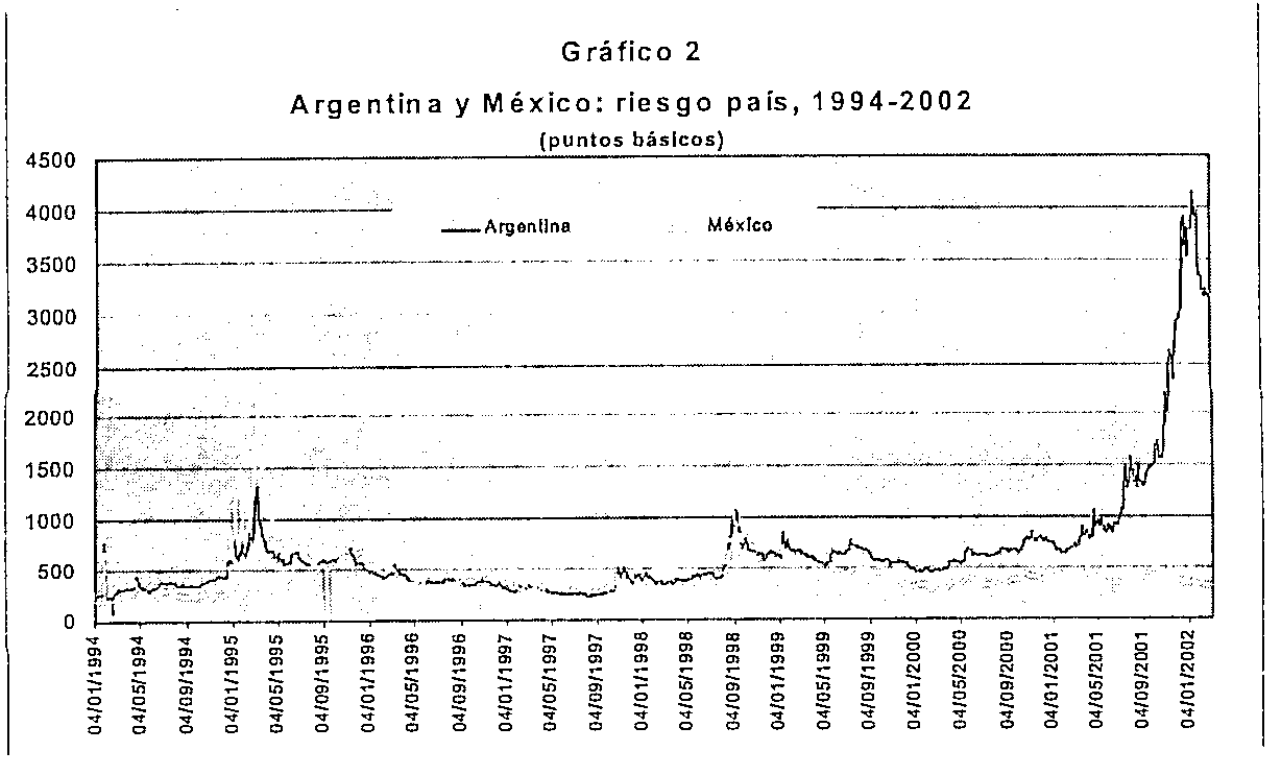

Fuente: JP Morgan. Aqui, el riesgo país se mide como la diferencia de la tasa de interés cobrada en los mercados internacionales al pals analizado con respecto a la de Estados Unidos. 


\section{Gráfico 3}

AMERICA LATINA: INESTABILIDAD DEL PRODUCTO INTERNO BRUTO, 1994-2001 a/ (Porcentajes de variación, con respecto al mismo trimestre del año anterior)

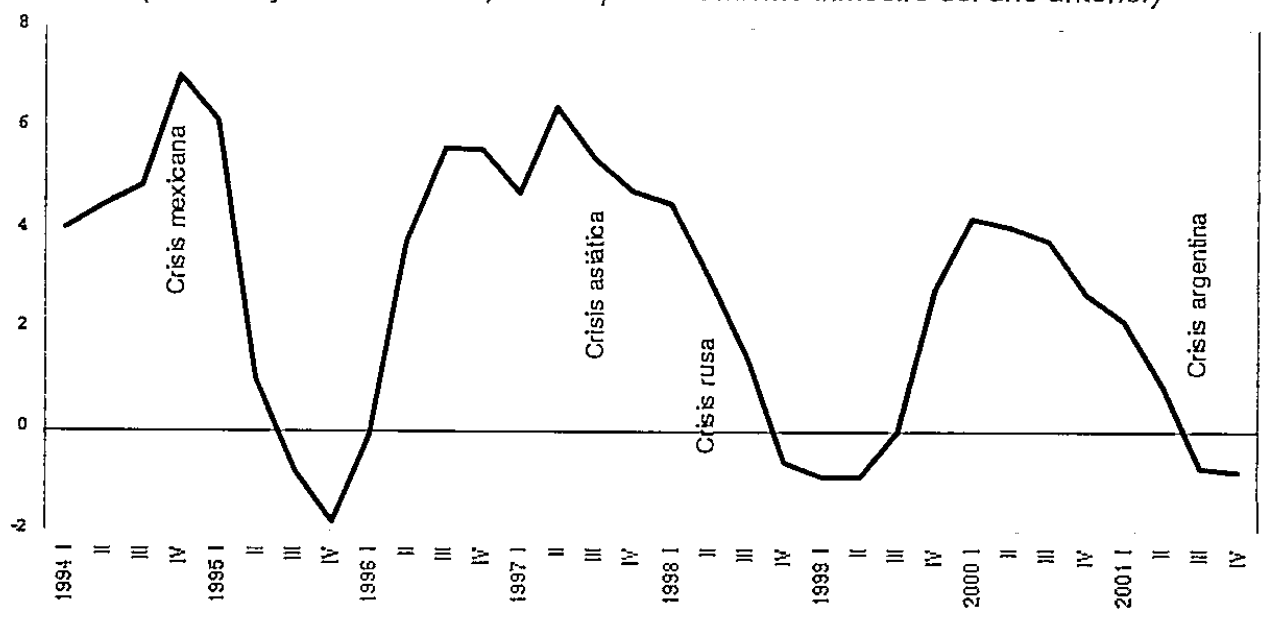

Fuente: CEPAL, sobre la base de cifras oficiales.

al Incluye Argentina, Brasil, Chile, Colombia, México, Perủ y Venezuela. 